\title{
Osteoblast adhesion and proliferation on porous chitosan / polycaprolactone scaffolds for bone tissue engineering application
}

\author{
Rashid Mad Jin b, Naznin Sultana, a, b, ${ }^{\star}$ \\ a Advanced Membrane Technology Research Centre (AMTEC), Universiti Teknologi Malaysia, 81310 Skudai, Johor, Malaysia \\ b Biomaterial Laboratory, Faculty of Biosciences and Medical Engineering, Universiti Teknologi Malaysia, 81310 Skudai, Johor Bahru, Malaysia \\ * Corresponding author: naznin@biomedical.utm.my
}

\section{Article history}

Received 5 May 2018

Revised 1 June 2018

Accepted 2 July 2018

Published Online 16 December 2018

\section{Graphical abstract}

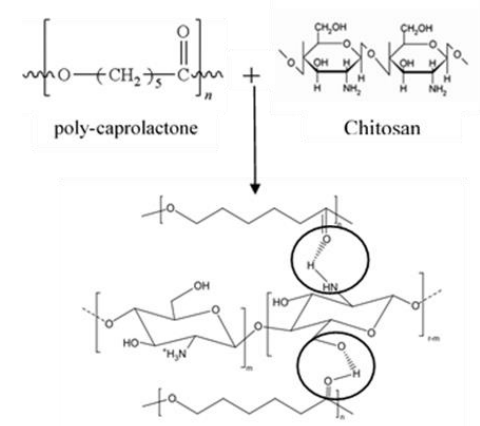

\begin{abstract}
Tissue engineering is an evolving technique to reduce the limitations of the bone graft. It provides diversity to improve the healing process of bone fractures and defect by combining the use of 3D scaffolds, healing promoting factors, gene therapy and different drugs. Flexibility to use a different technique to fabricate scaffolds lead to the new insight of bone healing future. A bone graft is defined as promoted bone healing through osteogenesis, osteoinduction, and osteoconduction by the implanted material alone or with other materials. Ideal bone graft depends on several factors such as biomechanical characteristic, tissue viability, the morphological structure as well as biological characteristics. In this work, we have investigated adhesion, proliferation, and differentiation of poly ( $\varepsilon$ caprolactone) / chitosan scaffolds with the incorporation of hydroxyapatite and tetracycline $\mathrm{HCl}$ on normal human osteoblast cells. Both of the polymers were blended without a cross-linking agent to form porous scaffolds by freeze-drying technique. From the results, it was observed that the compressive modulus increased from 4.0 MPa to $12.5 \mathrm{MPa}$ and the yield strength increased from 0.48 $\mathrm{MPa}$ to $0.75 \mathrm{MPa}$ for the PCL/CS scaffold and $\mathrm{nHA} / \mathrm{PCL} / \mathrm{CS}$ scaffold, respectively. Scanning electron microscopy study revealed that the cells successfully adhered to the surface of scaffolds after 24 hours incubation. Proliferation analysis exhibited increasing trend of growth of cells. This study indicated that the scaffold fabricated using this technique was able to promote adhesion, proliferation, and differentiation of normal human osteoblast cells.
\end{abstract}

Keywords: Tissue engineering, bone graft, normal human osteoblast cell, freeze drying technique, scaffolds.

(c) 2018 Penerbit UTM Press. All rights reserved

\section{INTRODUCTION}

Bone tissue engineering in the field of regenerative medicine has been extensively studied over the past two decades. In the recent years, the development of scaffolds-based tissue engineering provides alternatives to bone grafting for restoring the form and function of defect bones. In this technique, a combination of scaffolds, living cells, and bioactive factors are the fundamental to graft the engineering functional bone (Jan, H. et al., 2013).

Bone tissue engineering required a biocompatible scaffold that mimics the natural bone extracellular matrix (ECM) (Ami, R. A. et al., 2012). This characteristic was crucial as ECM in natural tissue support for cell attachment, proliferation as well as cell differentiation (Shuilin, W., et al., 2014). Other than that, it should have an ability to support the normal cellular activity such as molecular signaling system without any toxic effect on the host tissues (Shuilin, W. et al., 2014). Biomaterials for bone tissue engineering should possess physical, chemical and biological properties to support the growth of new cell formation (Ami, R. A. et al., 2012). Osteoinductive biomaterials have excellent characteristics as they are able to instructing its surrounding in vivo environment to induce ectopic bone formation (Ami, R. A. et al., 2012). One of the bioceramics, hydroxyapatite (HA) that is chemically similar to the inorganic component of bone matrix. It is biocompatible, bioactive and highly osteoconductive either in natural or synthetic form.
Different available methods to construct scaffolds with suitable properties have been extensively studied such as solid freeform fabrication (SFF) (Dietmar, W. H. et al., 2004), porogen leaching (Chun-Jie, L. et al., 2001), electrospinning (Muhammad, I., H. et al., 2014), gas foaming (Yoon, S. N. et al., 1999) freeze drying (Naznin, S. et al., 2012, Jin, R. M, et al., 2015) and many others. Different technique shall have different advantages and disadvantages.

Two polymers that will be studied in this research are chitosan and polycaprolactone (PCL). Chitosan is a natural polysaccharide that contains glucosamine and $\mathrm{N}$-acetylglucosamine, with a structure similar to that of glycosaminoglycans. Glycosaminoglycans are a major component of the native ECM. For this reason, chitosan shows excellent cell adhesion, proliferation, and differentiation. Besides, chitosan is known for its antibacterial properties (Croisier, F., \& Jérôme, C. 2013 and Dash, M., et al., 2011). However, as a single polymer, chitosan shows a lack of mechanical strength as well as a high degradation rate that makes it unstable to be used in tissue engineering applications. Another polymer is PCL, which is a synthetic polymer that has a good mechanical strength and a low biodegradation rate, and has also been used in tissue engineering. Despite that, its hydrophobicity causes poor cell adhesion and proliferation (Pitt, C. G., 1990). It is expected that blending both of the polymers will enhance its properties for bone tissue engineering applications.

In this experiment, freeze drying technique was utilized to fabricate PCL/CS composite scaffolds. Freeze drying or also known as 
lyophilization usually used in pharmaceutical industry to improve the stability of labile drugs. However, in recent years, this method has been explored to prepare porous materials for tissue engineering applications. The advantages of lyophilization included the chemical decomposition is minimized, removal of water or solvent without excessive heating, and enhanced product stability in a dry state (Nireesha, G. R., et al., 2013). Other than that, during the removal of solvent, this method uses ice crystal as porogens, there is no impurities are introduced into the samples so there is no need to further purifying the sample and most importantly with changing processing variables during freezing, it may produce materials with suitable pore morphologies and nanostructures (Qian, L. \& Zhang, H., 2011). The scaffolds prepared reported to have morphology mimicking natural sponge bone with a porous structure and higher pore interconnectivity. Pore structures and pore sizes are vital to tissue engineering applications, as they allow the harboring of cells, cell penetration, and migration, tissue ingrowth, vascularization, and nutrient supply within the targeted area (Armentano, I., et al., 2010).This morphology is important to obtain bone cell colonization and formation of bone tissue throughout entire scaffolds.

Moreover, nano-hydroxyapatite was added into the polymer solution to impart osteoconductivity of the scaffolds. Tetracycline hydrochloride $(\mathrm{TCH})$ is one of a wide range of antibiotics that are effective against various Gram-negative and Gram-positive microorganisms. The addition of antibiotic drugs is important since bone surgery has the risk of infiltrating pathogens such as Staphylococcus aureus, Staphylococcus epidermidis and many others (Cazalbou, S., Bertrand, G. \& Drouet, C., 2015).

To gain the further insight into prepared scaffolds, in vitro cell culture study with normal osteoblast cell (NHOst) was conducted. Normal human osteoblast cell study will provide the insight performance of the scaffolds as the implant for bone regeneration. The osteoblast is a fully differentiated cell that is responsible for the synthesis and mineralization of bone during bone formation and remodeling. It can produce many cell products such as enzymes alkaline phosphate and collagenase, growth factors, hormones and many others (Marco, A. V., Carlos, A. N. and Diego, A. G., 2015).

\section{EXPERIMENTAL}

\section{Materials}

Chitosan (medium molecular weight, 90\% degree deacetylation), Poly- $\varepsilon$-caprolactone (PCL) (molecular weight 70,000-80,000) were purchased from Sigma-Aldrich. Glacial acetic acid, sodium hydroxide $(\mathrm{NaOH})$, phosphate-buffer saline (PBS) and all other materials were analytical grade. NHOst were bought from Lonza Walkersville, Inc. contains osteoblast basal medium (OBM) and osteoblast growth medium (OGM: Fetal bovine serum (FBS), Ascorbic acid). Trypsin/ EDTA, HEPES buffered saline solution and trypsin neutralizing solution (TNS). VEGF has been used as growth factors and was added to the medium. Other consumable such as serological pipette individual wrapped $(1,2,5,10$ and $25 \mathrm{~mL})$, tissue culture flask $(25$ and $75 \mathrm{~cm} 2)$, centrifuge tube and many other purchased from ATCC Company (USA)..

\section{Fabrication of PCL/chitosan composite scaffolds}

$1.0 \mathrm{~g}$ of PCL was weighed and dissolved in $20 \mathrm{~mL}$ of $2 \%$ glacial acetic acid. The solution was stirred using a magnetic stirrer. Then $0.4 \mathrm{~g}$ of chitosan was added to the solution and kept stirring until the solution became a clear viscous solution. A hand held homogenizer (IKA UltraTurax, model T25, Germany) was used to homogenize the solution. Following this, the homogenized solution was molded in a capped glass tube. The glass tube was immediately kept in a freezer at $-80^{\circ} \mathrm{C}$ and was solidified overnight. The frozen emulsion was transferred to the freeze dryer vessel and lyophilized for 72 hours to remove water and the solvent phase. The prepared scaffolds were transferred into a desiccator and kept until evaluation. 10\% $\mathrm{nHA}(\mathrm{g} / \mathrm{g})$ was then added to the solution. The mixture was homogenized and transferred into glass vials. The process was continued with freezing and lyophilization. $0.04 \mathrm{~g}$ Tetracycline hydrochloride (TCH) was loaded into the scaffolds as described previously (Rashid. M. J. et al., 2015).

\section{Characterization of PCL/chitosan scaffolds}

The scaffolds were examined under SEM (Hitachi TM-3000, Japan) and field emission scanning microscopy (FESEM, Hitachi SU8000, Japan). An Energy dispersive X-ray (EDX) was used to study the elemental analysis of the scaffold. ATR-FTIR spectroscopy was used to identify the presence of functional groups in scaffold specimen. The compressive mechanical properties of the scaffolds were tested with an Instron mechanical tester (Instron 5848, USA). The bioactivity test for surface modification was done by immersing the scaffolds in Simulated Body Fluid (SBF). The SBF were prepared mimicking human blood plasma that contain ion concentration of $\mathrm{Na}^{+} 142.0, \mathrm{~K}^{+}$ 5.0, $\mathrm{Mg}^{2+} 1.5, \mathrm{Ca}^{2+} 2.5, \mathrm{Cl}^{-} 47.8, \mathrm{HCO}_{3}-4.2, \mathrm{HPO}_{4}{ }^{2-} 1.0$ and $\mathrm{SO}_{4}{ }^{2-} 0.5$ $\mathrm{mM}$ (Kokubo et al., 2003).

\section{RESULTS AND DISCUSSION}

\section{Bioactivity assessment of bio-nanocomposites}

The osteogenic potential of the composites can be evaluated by submerging the scaffolds in simulated body fluid (SBF) to form apatite layer (Marc, B. and Jacques, L., 2009). This method has become the "gold standard" to ascertain whether materials are biocompatible or not since the invention of SBF by Kokubo et al. in 1990 (Wu, S., et al., 2014).

In the bioactivity assay of the scaffold, SBF solution was used as a medium. The samples were placed in $50 \mathrm{ml}$ centrifuge tubes containing $20 \mathrm{ml}$ of SBF solution sealed with parafilm. The centrifuge tube was kept in a shaking water bath at $37^{\circ} \mathrm{C}$ and shaken at $40 \mathrm{rpm}$ to ensure that fluid flowed through the entire scaffold. The SBF was renewed every 7 days. The results were positive for the formation of an apatite layer on the surface of scaffolds. SEM micrographs of apatite layer $(\mathrm{Ca} / \mathrm{P})$ deposited on the surface of scaffolds after 3 weeks immersed in the simulated body fluid (SBF) solution are shown in Fig. 1. It can be seen from the Fig. 1 that the apatite layer was covering most of the surface of the scaffolds.
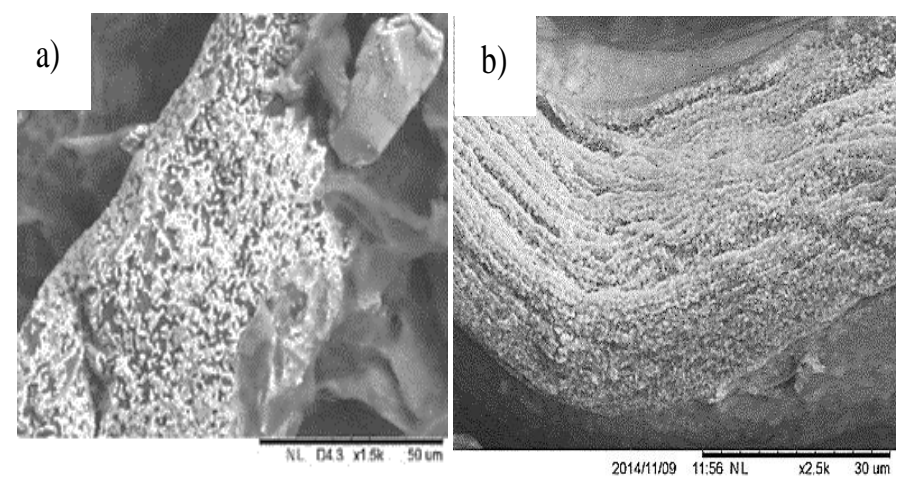

Fig. 1 SEM micrograph of apatite layer $(\mathrm{Ca} / \mathrm{P})$ deposited on the surface of scaffolds after 3 weeks immersed in the simulated body fluid (SBF) solution. SEM images a) $\mathrm{nHa} / \mathrm{PCL} / \mathrm{CS}$ and b) $\mathrm{nHA} / \mathrm{PCL} / \mathrm{CS} / \mathrm{TCH}$.

Further information on the elemental composition of the samples can be provided by EDX analysis. Fig. 2 shows the EDX spectrum of PCL/CS scaffolds after 3 weeks immersion which proved that the apatite formation on the surface of PCL/CS scaffolds was $\mathrm{Ca} / \mathrm{P} . \mathrm{Ca} / \mathrm{P}$ ratio 1.8 was higher compared to $\mathrm{nHA}$ prepared using nanoemulsion technique. The ratio of $\mathrm{Ca} / \mathrm{P}$ is dependent on the technique fabricated and SBF immersion has a higher concentration of ion that increases the $\mathrm{Ca} / \mathrm{P}$ ratio nucleated to the surface of scaffolds. SBF immersion work based on the chemical bioactive mechanism that may allow certain biomaterials to form apatite layer on its surface. SBF system is metastable and eventually become thermodynamically stable by performing apatite crystal (Marc, B. and Jacques, L., 2009). Based on the previous study, it shows that SBF immersion test only gives information on chemical bioactive mechanism and only a part of the complex mechanism of bone resorption and formation (Haobo, P., Xioali, Z., Brian, W. D. and William, W. L., 2010). 
a)

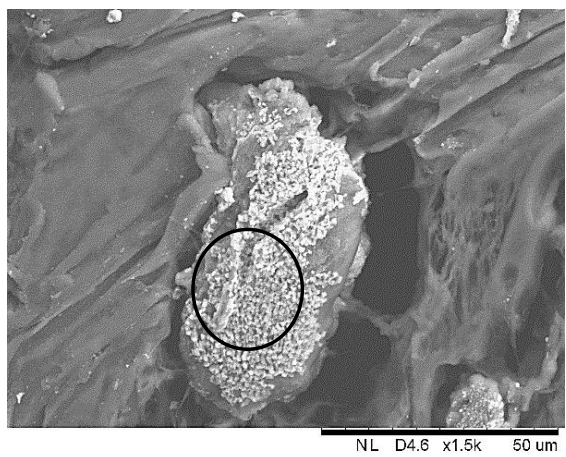

b)

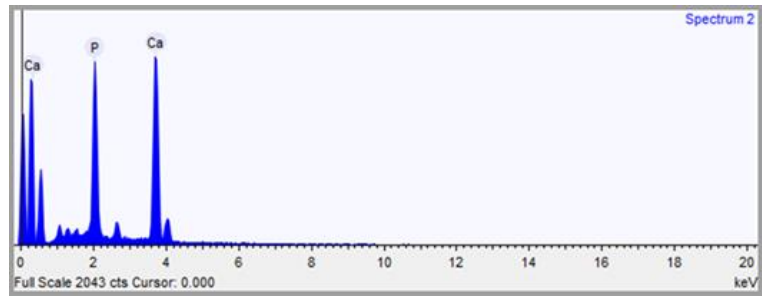

\begin{tabular}{llll}
\hline Element & $\begin{array}{l}\text { Weight } \\
\%\end{array}$ & $\begin{array}{l}\text { Weight } \\
\% \text { }\end{array}$ & $\begin{array}{l}\text { Atomic } \\
\%\end{array}$ \\
\hline Phosphorus & 35.102 & 0.441 & 41.173 \\
Calcium & 64.898 & 0.441 & 58.827 \\
\hline
\end{tabular}

Fig. 2 SEM micrograph of a) PCL/CS scaffold with apatite deposition (b) EDX spectrum and (c) Table of the elemental component percentage of $\mathrm{Ca} / \mathrm{P}$ deposited on PCL/CS scaffolds after 3 weeks immersion (analysis on the area in a circle in a).

Mechanical properties of the scaffold should match the host bone tissue properties and have proper load transfer to support harboring of new bone tissues and support and also the mechanical integrity of the implanted area (Hannink, G. and Arts, J. C., 2011). In this research, the compressive mechanical properties of the scaffolds were tested and Table 1 shows the compressive yield strength and compressive modulus of all the scaffolds. It was found that both the compressive modulus and yield strength increased with the addition of HA. Table 1 shows that the same processing conditions led to a varied compressive modulus from 4.0 to $12.5 \mathrm{MPa}$, and a yield strength of 0.48 and 0.75 $\mathrm{MPa}$ for the PCL/CS scaffold and nHA/PCL/CS scaffold, respectively. From the statistical analysis, it was found that both the compressive modulus and the compressive yield strength of the PCL/chitosan scaffolds were significantly different to those of nHA/PCL/chitosan scaffolds $\left(\mathrm{p}^{*}<0.05\right)$. These data demonstrate the positive effects of the addition of nHA in enhancing the mechanical properties of scaffolds. It was also found that the compressive modulus and yield strength of the HA/PCL/CS scaffold were not significantly different than HA/PCL/CS/TCH $(p<0.05)$ scaffold. These results show that the incorporation of $\mathrm{TCH}$ did not change the mechanical strength of the scaffolds.

Table 1 Compressive yield strength and compressive modulus of scaffolds.

\begin{tabular}{ccc}
\hline Scaffolds & $\begin{array}{c}\text { Compressive } \\
\text { yield strength } \\
(\mathrm{MPa})\end{array}$ & $\begin{array}{c}\text { Compressive } \\
\text { modulus (MPa) }\end{array}$ \\
\hline PCL/CS & $0.48 \pm 0.05$ & $4.0 \pm 0.2$ \\
nHA/ PCL/CS & $0.75 \pm 0.06$ & $12.5 \pm 0.5$ \\
nHA/ & $0.75 \pm 0.08$ & $12.1 \pm 0.1$ \\
\hline PCL/CS/TCH & & \\
\hline
\end{tabular}

\section{In vitro cell culture study}

In this research, PCL/chitosan-based scaffolds were fabricated for bone tissue engineering applications. Normal human osteoblast cell studies will provide insight into the performance of the scaffolds as an implant for bone regeneration. The osteoblast is a fully differentiated cell that is responsible for the synthesis and mineralization of bone during bone formation and remodeling. It can produce many cell products such as the enzymes alkaline phosphate and collagenase, growth factors, hormones and many others (Velasco, M. A., NarváezTovar, C. A. and Garzón-Alvarado, D. A., 2015).

The adhesion of osteoblast cells onto the surface of scaffolds is a crucial step enabling the cells to proliferate and differentiate further. To investigate the growth of NHOst cells on the scaffolds, PCL/CS scaffolds were seeded with NHOst cells and incubated for 24 hours before the cells were fixed and analyzed using SEM. Figure 4.3 shows single osteoblast cells after 24-hours of incubation. The white round shape shows the body and nucleus, and cellular cytoplasmic extensions (lamellipodia and filopodia extensions) anchoring the surface of the scaffolds are labeled with a black arrow (Machado, R. et al. 2013; PonOn, W. et al., 2013; Svetlane, S., Khaddiatou, G., and Treena. L., A., 2015). The cells are anchored between two pores of the scaffolds. NHOst cells have a polygonal shape with a size in the range from 10 $30 \mu \mathrm{m}$

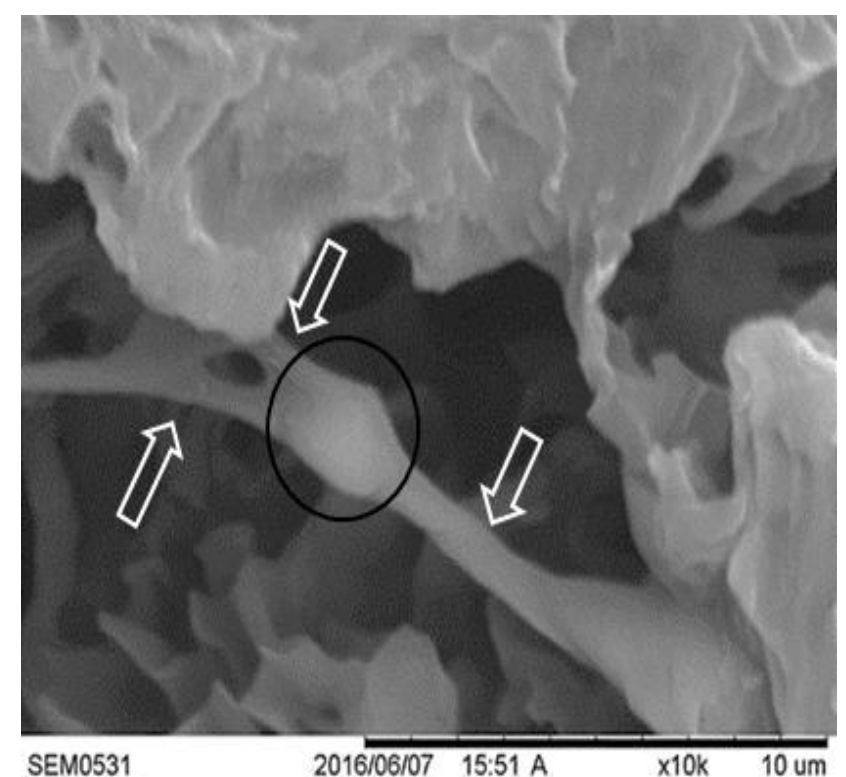

Fig. 3 SEM micrograph of a single osteoblast cell, anchoring the between two pores of the scaffolds. The white circle indicates the body or nucleus, while black arrows indicate long conical protrusions or dendritic extensions.

The vitality of osteoblasts is important to determine the bone formation. Thus, bone is formed by the mineralization of an organic matrix (largely collagen), through the nucleation and growth of minerals (HAp) regulated by osteoblasts (Harada, S., \& Rodan, G. A. 2003 and Liao, C. J., et al.. 2000). A sample of scaffolds was seeded with osteoblast cells for 7 days to determine the biomineralization process which occurs in the presence of osteoblast cells on the surface of scaffolds. The results as in figure 4 show good apatite nucleation that covering most of the area with accumulation of osteoblast cell. Nucleation of apatite and extracellular matrix (ECM) formation after seeded with NHOst cell are on the surface of the scaffolds meanwhile corporation of synthesis nHA are covered within the polymer blends. The apatite nucleation occurs at the edge of pore wall and inside the pore of the scaffold. 
a)

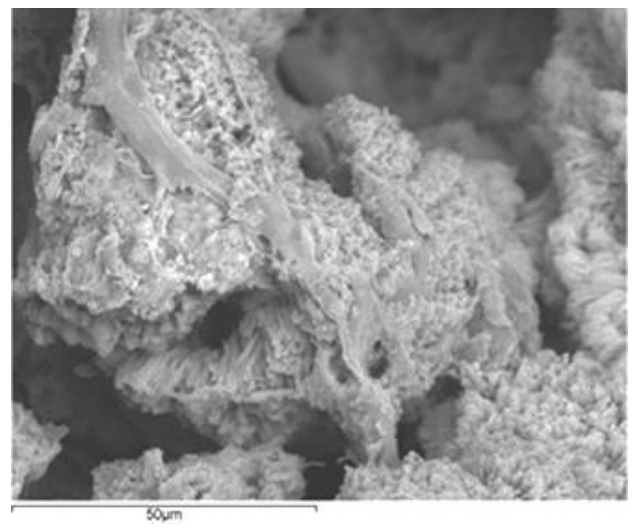

b)

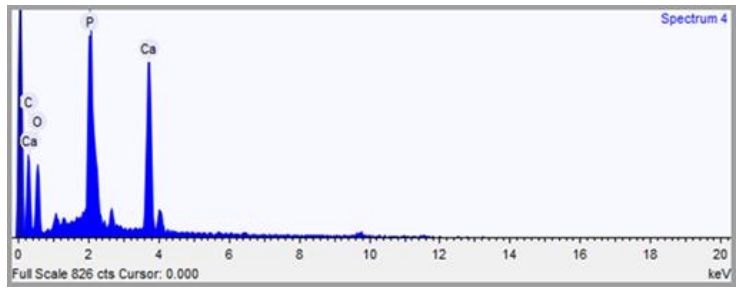

C)

\begin{tabular}{cccc}
\hline Element & $\begin{array}{c}\text { Weight } \\
\%\end{array}$ & $\begin{array}{c}\text { Weight } \\
\% \text { }\end{array}$ & $\begin{array}{c}\text { Atomic } \\
\%\end{array}$ \\
\hline Carbon & 32.918 & 1.125 & 47.080 \\
Oxygen & 35.078 & 1.117 & 37.663 \\
Phosphorus & 12.225 & 0.421 & 6.780 \\
Calcium & 19.779 & 0.530 & 8.477 \\
\hline
\end{tabular}
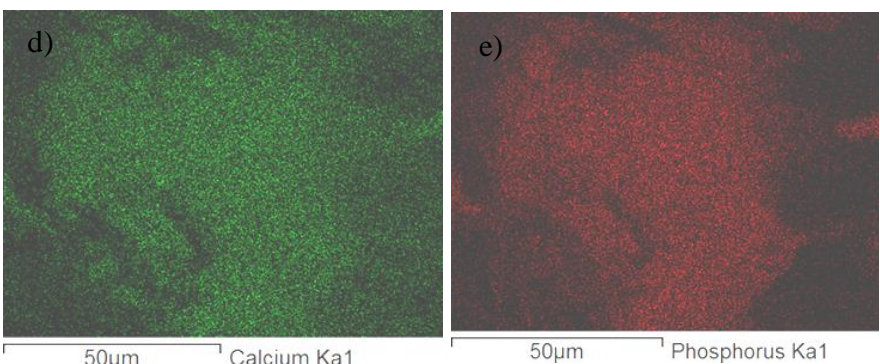

Fig. 4 Illustrates the a) SEM micrograph of nHA/PCL/CS b) EDX spectrum, c) Table of elemental component percentage of $\mathrm{Ca} / \mathrm{P}$ deposited Elemental mapping d) calcium and e) phosphorous.

Further analysis with EDX analysis proved that the apatite layer was $\mathrm{Ca} / \mathrm{P}$ and from the elemental component, the ratio of $\mathrm{Ca} / \mathrm{P}$ is higher compared to the prepared one. The ratio $\mathrm{Ca} / \mathrm{P}$ is 2.66 and the prepared one is 1.6 . The only reason $\mathrm{Ca} / \mathrm{P}$ is higher because in the present of NHOst the process of apatite nucleation is different with solely depend on NHOst cells. From the proposed mechanism by Suwimon, B et al 2012, it stated that amorphous calcium phosphate and ionic calcium stored in mitochondria is transported via vesicles to the ECM before converting to more crystalline apatite. This process should produce the same $\mathrm{Ca} / \mathrm{P}$ ratio. The different in $\mathrm{Ca} / \mathrm{P}$ ratio may cause by the difference in ion concentration of the medium (Suwimon, B et al 2012). Other than that, osteoblast cell has previously found to likely adhere on positively charged surface area compared to the negatively charged surface of scaffolds (Amaral, I. F et al. 2007). Chitosan that has cationic nature and PCL has the surface area that allowed the osteoblast cells to adhered and proliferated on the surface of scaffolds. Other than that, scaffolds prepared by freeze drying technique possessed interconnected porous structures. Where, the cells seeded able to migrate into the pore to multiply the cells numbers with allowing the mass transfer of oxygen, nutrient as well as waste metabolic products (Marco, A. V., Carlos, A. N., and Diego, A. G. 2015).

\section{CONCLUSION}

Freezing and lyophilization technique successfully fabricated threedimensional design that provides a suitable microenvironment for cells for proliferation and differentiation. Addition of hydroxyappatite (nHA) and Tetracycline $\mathrm{HCl}(\mathrm{TCH})$ showed enhanced cellular activity among the different types of scaffolds. The scaffolds possessed suitable properties and thus recommended for bone tissue engineering applications.

\section{ACKNOWLEDGEMENT}

This work was financially supported by the Universiti Teknologi Malaysia under the Research University Grant, Hi-COE vot (4J191) and Ministry of Higher Education Malaysia.

\section{REFERENCES}

Amaral, I. F., Cordeiro, A. L., Sampaio, P., Barbosa, M. A. (2007). Attachment, spreading and short-term proliferation of human osteoblastic cells cultured on chitosan films with different degrees of acetylation. Journal of Biomaterials Science, Polymer Edition, 18(4): 469-485.

Ami, R. A., Cato. T. L., Syam P. N. 2012. Bone tissue engineering: Recent advances and challenges. Biomedical Engineering. 40(5): 363-408.

Armentano, I., Dottori, M., Fortunati, E., Mattioli, S., Kenny, J. M. 2010. Biodegradable polymer matrix nanocomposites for tissue engineering: A review. Polymer Degradation and Stability, 95(11): 2126-2146.

Boonrungsiman, S., Gentleman, E., Carzaniga, R., Evans, N. D., McComb, D. W., Porter, A. E., Stevens, M. M. (2012). The role of intracellular calcium phosphate in osteoblast-mediated bone apatite formation. Proceedings of the National Academy of Sciences, 109(35), 14170-14175.

Cazalbou, S., Bertrand, G., Drouet, C. 2015. Tetracycline-loaded biomimetic apatite: An adsorption study. The Journal of Physical Chemistry B, 119(7): 3014-3024.

Chien, H. H., Lin, W. L., Cho, M. I. (2000). Down-regulation of osteoblastic cell differentiation by epidermal growth factor receptor. Calcified Tissue International, 67(2), 141-150.

Croisier, F., Jérôme, C. (2013). Chitosan-based biomaterials for tissue engineering. European Polymer Journal, 49(4): 780-792.

Dash, M., Chiellini, F., Ottenbrite, R. M., Chiellini, E. 2011. Chitosan - a versatile semi-synthetic polymer in biomedical applications. Progress in Polymer Science, 36(8): 981-1014.

Dietmar, W. H., Micheal, S. and Makarand, V. R. 2004. Scaffold-based tissue engineering: rationale for computer-aided design and solid free-form fabrication systems. Trends in Biotechnology, 22(7), 354-62.

Eliopoulos, G. M., Eliopoulos, G. M., Roberts, M. C. (2003). Tetracycline therapy: update. Clinical Infectious Diseases, 36(4), 462-467.

Fotakis, G., Timbrell, J. A. 2006. In vitro cytotoxicity assays : Comparison of LDH, neutral red, MTT and protein assay in hepatoma cell lines following exposure to cadmium chloride, Toxicology Letters, 160: 171-177.

George, F., John. A. T. 2006. In vitro cytotoxicity assays : Comparison of LDH, neutral red, MTT and protein assay in hepatoma cell lines following exposure to cadmium chloride. Toxicology Letter, 160, 171-177.

Haobo, P., Xioali, Z., Brian, W. D., William. W. L.2010. Apatite-formation ability - predictor of "bioactivity. Acta Biomaterialia. 6, 4181-4188.

Harada, S. I., Rodan, G. A. (2003). Control of osteoblast function and regulation of bone mass. Nature, 423(6937), 349.

Henkel, J., Woodruff, M. A., Epari, D. R., Steck, R., Glatt, V., Dickinson, I. C., ... \& Hutmacher, D. W. (2013). Bone regeneration based on tissue engineering conceptions - a 21st century perspective. Bone Research, 1(3), 216.

Jin, R. M., Sultana, N., Baba, S., Hamdan, S., Ismail, A. F. (2015). Porous $\mathrm{pcl} / \mathrm{chitosan}$ and $\mathrm{nha} / \mathrm{pcl} / \mathrm{chitosan}$ scaffolds for tissue engineering applications: fabrication and evaluation. Journal of Nanomaterials, 16(1), 138.

Kokubo, T., Kim, H.-M., Kawashita, M. 2003. Novel bioactive materials with different mechanical properties. Biomaterials, 24(13): 2161-2175.

Liao, C. J., Chen, C. F., Chen, J. H., Chiang, S. F., Lin, Y. J., Chang, K. Y. (2002). Fabrication of porous biodegradable polymer scaffolds using a solvent merging/particulate leaching method. Journal of Biomedical 
Materials Research: An Official Journal of The Society for Biomaterials, The Japanese Society for Biomaterials, and The Australian Society for Biomaterials and the Korean Society for Biomaterials, 59(4), 676-681.

Lochmann, D., Zimmer, A. 2005. A practical note on the use of cytotoxicity assays. International Journal of Pharmaceutics, 288: 369-376.

Machado, R., Da Costa, A., Sencadas, V., Garcia-Arévalo, C., Costa, C. M., Padrao, J., Casal, M. 2013. Electrospun silk-elastin-like fibre mats for tissue engineering applications. Biomedical Materials, 8(6): 065009.

Marc, B., Jacques, L., 2009. Biomaterials Can bioactivity be tested in vitro with SBF solution?. Biomaterials. 30, 2175-2179.

Marco, A. V., Carlos, A. N., Diego, A. G. 2015. Design, materials, and mechanobiology of biodegradable scaffolds for bone tissue engineering, BioMed Research International, 2015: 1-21.

Muhammad, I., H., Tao, S., Naznin, S. 2014. Fabrication of Nanohydroxyapatite/Poly (caprolactone) composite microfibers using electrospinning technique for tissue engineering applications. Journal of Nanomaterials, 2014, 65.

Nam, Y. S., Yoon, J. J., Park, T. G. (2000). A novel fabrication method of macroporous biodegradable polymer scaffolds using gas foaming salt as a porogen additive. Journal of Biomedical Materials Research: An Official Journal of The Society for Biomaterials, The Japanese Society for Biomaterials, and The Australian Society for Biomaterials and the Korean Society for Biomaterials, 53(1), 1-7.

Naznin, S., Min, W. 2012. PHBV/PLLA-based composite scaffolds fabricated using an emulsion freezing/freeze-drying technique for bone tissue engineering: Surface modification and in vitro biological evaluation. Biofabrication, 4(1): 15003.

Nireesha, G. R., Divya, L., Sowmya, C., Venkateshan, N., Babu, M. N., Lavakumar, V. (2013). Lyophilization/freeze drying - an review. International Journal of Novel Trends in Pharmaceutical Sciences, 3(4), 87-98.

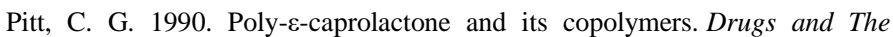
Pharmaceutical Sciences, 45: 71-120.

Pon-On, W., Charoenphandhu, N., Teerapornpuntakit, J., Thongbunchoo, J., Krishnamra, N., Tang, I. M. 2013. In vitro study of vancomycin release and osteoblast-like cell growth on structured calcium phosphatecollagen. Materials Science and Engineering C, 33(3): 1423-1431.

Qian, L., Zhang, H. 2011. Controlled freezing and freeze drying: A versatile route for porous and micro-/nano-structured materials. Journal of Chemical Technology and Biotechnology, 86(2): 172-184.

Raul, M., Andre, D., C., Vitor, S., Carmen. G., Carlos, M., C., Jorge, P., Andreia G., Senentxu. L., Jose, C. R., Margarida, C. 2013. Electrospun silk-elastinlike fibre mats for tissue engineering applications. Biomedical Materials, 8(6): 065009.

Shuilin, W., Xiangmei, L., Kelvin, W. K. Y., Changsheng, L., Xianjin, Y., 2014. Biomimetic porous scaffolds for bone tissue engineering. Material Science and Engineering, 80: 1-36.

Susmita, B., Solaiman. T. 2012. Calcium phosphate ceramic systems in growth factor and drug delivery for bone tissue engineering: A review. Acto Biomaterialia, 8(4): 1401-1421.

Svetlane, S., Khaddiatou, G., Treena. L., A. 2015. In Vitro and In Vivo Evaluation of Composite Scaffolds for Bone Tissue Engineering. Handbook of Bioceramics and Biocomposites. Switzerland: Springer International Publishing.

Tong, S., Xue, L., Xu, D. P., Liu, Z. M., Du, Y., Wang, X. K. 2016. In vitro culture of hFOB1. 19 osteoblast cells on TGF- $\beta 1$-SF-CS three-dimensional scaffolds. Molecular Medicine Reports, 13(1): 181-187.

Tong, S., Xue, L., Xu, D. P., Liu, Z. M., Du, Y., Wang, X. K. (2016). In vitro culture of hFOB1. 19 osteoblast cells on TGF- $\beta 1$-SF-CS three-dimensional scaffolds. Molecular Medicine Reports, 13(1), 181-187.

Velasco, M. A., Narváez-Tovar, C. A., Garzón-Alvarado, D. A. (2015). Design, materials, and mechanobiology of biodegradable scaffolds for bone tissue engineering. Biomed Research International, 2015.

Wu, S., Liu, X., Yeung, K. W., Liu, C., Yang, X. 2014. Biomimetic porous scaffolds for bone tissue engineering. Materials Science and Engineering R: Reports, 80: 1-36. 